\title{
Protection Intimidation Related with Big Data
}

\author{
N.Sivaranjani, Amudha S, Mary Linda I
}

\begin{abstract}
In this paper, we have a tendency to tend to look at security problems for distributed computing, massive info, Map downsize and Hadoop condition. the foremost concentrate is on security problems in distributed computing that unit of measurement known with monumental info. Brobdingnag Ian information applications unit of measurement an outstanding profit to associations, business, firms and tons of in depth scale and modest scale enterprises. we have a tendency to moreover point out fluctuated realizable answers for the problems in distributed compute defense and Hadoop. Distributed compute defense is making at a fast pace which contains computer security, organize security, info security, and information protection. Distributed computing assumes a horrendously essential half in defensive information, applications and during this manner the associated foundation with the assistance of ways, advancements, controls, and large information devices. Besides, distributed computing, mammoth information and its applications, edges unit of measurement apparently to talk to the fore most encouraging new wildernesses in science.
\end{abstract}

Keywords : Cloud Computing, Big Data, Hadoop,Map Reduce, HDFS (Hadoop Distributed File System)

\section{INTRODUCTION}

On explore propelled info and to spot designs it's imperative to immovably store, handle and share monster measures of innovative info. Cloud accompanies a particular security challenge, i.e. the knowledge man of affairs won't have any administration of wherever the knowledge is concerning. the rationale for this administration issue is that inside the event that one wishes to incite the benefits of distributed computing, he/she ought to likewise use the portion of assets and what's a lot of the programing given by the controls. on these lines it's required to defend the $\mathrm{d}$ ata inside the inside of naughty procedures.

Since cloud includes broad quality, we've a bent to tend to trust that as hostile giving associate all encompassing response to securing the cloud, it's planning to be glorious to frame vital upgrades in securing the cloud that is in a position to ultimately provide $\mathrm{u}$. $\mathrm{s}$. with a protected cloud.

Google has conferred Map reduce [1] system for technique monster measures of information on ware instrumentation. Apache's Hadoop disseminated recording

framework (HDFS) is advancing as associate unmatched programming 0.5 for distributed computing consolidated

Revised Manuscript Received on October 22, 2019.

N.Sivaranjani, Department of Computer science and Engineering, Bharath Institute of Higher Education and Research, Chennai, Tamilnadu, India. Email: ranjibalas@gmail.com

Amudha S, Department of Computer science and Engineering, Bharath Institute of Higher Education and Research, Chennai, Tamilnadu, India..

Mary Linda I, Department of Computer science and Engineering, Bharath Institute of Higher Education and Research, Chennai, Tamilnadu, India. Email: catchlin.18@gmail.com Email: amudha17s@gmail.com

adjacent to coordinated segments like Map reduce. Hadoop, that is associate code content document usage of Google Map reduce, also as a sent recording framework, offers to the machine laptop soul the reflection of the guide and so the decrease. With Hadoop it's less tight for associations to instigate a balance on the big volumes of information being created on a routine, however at a comparable time would possibly likewise deliver issues connected with security, information get to, checking, high openness and business harmoniousness.

During this paper, we've a bent to tend to return up with some methodologies in giving security. we've a bent to tend to got to a framework which will scale to the touch upon associate outsized assortment of internet sites and even be able to technique massive and enormous measures of information. Be that as a result of it'd, innovative frameworks using HDFS and Map reduce aren't specifically enough/adequate inferable from the very certainty that they are doing not offer required safety efforts to secure delicate learning. to boot, Hadoop system is utilized to figure out issues and handle information helpfully by abuse very stunning procedures like consolidating the $\mathrm{k}$-implies with information handling innovation [3].

A.Cloud Computing Distributed computing could also be Associate in Nursing innovation that depends upon sharing of method assets than having close to servers or individual gadgets to agitate the applications. In Cloud Computing, "Cloud" proposes that "The Internet", throughout this fashion Cloud Computing recommends that a kind of computation amid that administrations unit sent through world wide web. the target of Cloud Computing is to frame utilization of quickening registering energy to execute uncountable bearings every second. Distributed computing utilizes systems of Associate in Nursing outsize bunch of servers with express associations with flow into getting ready among the servers. as opposition fitting a laptop computer code suite for each laptop computer, this innovation needs to place in associate degree extremely solitary laptop computer code in each laptop computer that grants purchasers to sign into a Web-based administration that likewise has all of the comes required by the buyer. there is a basic work move, in associate degree extremely distributed computing framework. Neighborhood PCs not got to be compelled to be affected to want the entire weight once it includes running applications. Distributed computing innovation is getting accustomed cut back the use worth of computation assets [4]. The cloud prepare, comprising of a system of PCs, handles the heap. the worth of laptop computer code and instrumentality on the buyer complete declines. the foremost issue that has to be done at the client's complete is to run the cloud interface laptop computer code to hitch to the cloud. Distributed computing includes of a front and posterior. 
The front incorporates the client's laptop computer and laptop computer code expected to induce to the cloud prepare. posterior includes of organized PCs, servers and knowledge frameworks that make the cloud. the buyer will get to applications at intervals the cloud organize from wherever by associating with the cloud abuse world wide web. variety of the $\$ 64000$ time applications that utilization Cloud Computing ar Gmail, Google Calendar, Google Docs and Dropbox and so on.,

B.Big knowledge Brobdingnagian knowledge is that the word acclimated depict Brobdingnagian volumes of organized and unstructured learning that square measure on these lines monstrous that it's appallingly robust to strategy this knowledge abuse recent databases and portable computer code advances. The expression "Enormous knowledge [5]" is organizations international organisation agency needed to take care of around organized awfully giant unfold learning. the 3 primary terms that imply monumental learning have the subsequent properties: a) Volume: several parts contribute towards increasing Volume spilling learning and data gathered from sensors so forth., b) Variety: recently knowledge comes on the entire kinds of organizations messages, video, sound, exchanges so forth., c) Velocity: this recommends speedy the data is being created and conjointly the approach quick the knowledge ought to be able to satisfy the request. the opposite a combine of measurements that require to ponder with importance giant knowledge square measure Variability and complexity [5].

C.Map decrease Hadoop Map downsize can be a structure usual compose applications that strategy mammoth measures of information in parallel on groups of merchandise instrumentality assets amid a solid, blame tolerant technique. A Map downsize work beginning partitions the data into singular lumps that unit prepared by Map occupations in parallel. The yields of the maps organized by the system unit then contribution to the scale back errands. For the foremost 0.5 the knowledge and what is more the yield of the need unit each continue amid a record framework. Booking, observation and re-executing falling flat errands unit taken care by the structure.

D. Hadoop Distributed classification system (HDFS) HDFS can be a recording framework that traverses all of the hubs amid a Hadoop bunch for learning storage. It connects on documenting frameworks on native hubs to create it into one monstrous record framework. HDFS enhances unwavering quality by imitating learning over varied sources to beat hub disappointment.

\section{RELATED WORK}

Hadoop (a distributed computing structure), a Java based totally for the foremost 0.5 disseminated framework, may possibly be another system inside the market. Since Hadoop is new and up to now being created to target further choices, there unit variety of security issues that require to be cared-for. Analysts have acknowledged variety of the issues and commenced player in on this. variety of the hanging results, that is processed to our house and helped America to research, unit given below[6].

The earth Wide net pool has acknowledged the importance of SPARQL that might be used as a part of assorted data sources. Later on, the possibility of secured question was anticipated thus on broaden protection in protection/utility trade. Here, Jelena, of the USC logical train Institute, has processed that the queries unit of prepared with regards to the arrangement of the provider, rather than all inquiry procedure. Bertinoetal written a paper on get to administration for XML Documents [8]. inside the paper, cryptography and advanced mark technique unit processed, and systems of access management to XML data report is worried for secured climate. Later on, he written another paper on factual outsider XML report circulation [9] that required another place stock in layer of security to the worldview. Kevin Hamlen associate degreed et al anticipated that data unit of suspend on amid an info disordered rather than plain content. The advantage of putt away data encoded is that yet assuming entrant will get into the knowledge, he or she cannot get the precise data. In any case, the inconvenience is that writing needs numerous overhead. as important technique the plain content, the majority of the operation can occur in scientific discipline kind.

Throughout this technique the approach of technique in field kind further to security layer. IBM specialists collectively processed that the inquiry procedure have to be compelled to occur amid a secured state of affairs. At that point, the work of Kerberos has been to a wonderful degree compelling. Kerberos is nothing however a gathering of validation that has been created at university[7]. They have worked upon scientific positive potential protection infringement that averts data spill on the means side data supplier's arrangement. the higher than works have compact America, that we have a tendency to tend to unit examining changed ways that during which to influence frame the cloud climate safer for data exchange and calculation.

\section{PROBLEMS AND CHALLENGES}

Distributed computing accompanies fluctuated security issues due to it includes a handful of advancements and to boot systems, databases, operational frameworks, virtualization, and booking, dealings administration, stack leveling , timing administration and memory administration. after, security issues with these frameworks and innovations territory unit material to distributed computing. as Associate in Nursing example, it's imperative for the system that interconnects the frameworks in a very notably cloud to be secure.

Additionally, virtualization worldview in distributed computing prompts varied security concerns. as Associate in Nursing example, mapping of the virtual machines to the physical machines ought to be performed really immovably. knowledge security not fully includes the writing of the knowledge, however place along guarantees that applicable arrangements vary unit actualized for data sharing. Moreover, and allotment and memory administration calculations even ought to be secure.

The big data issues zone unit most intensely felt in on the way facet any doubt businesses, as Associate in Nursing example, telecoms, web giving and business, retail and cash administrations, and on the way facet any doubt government exercises. the knowledge blast goes to frame life exhausting throughout a number of businesses, and conjointly the

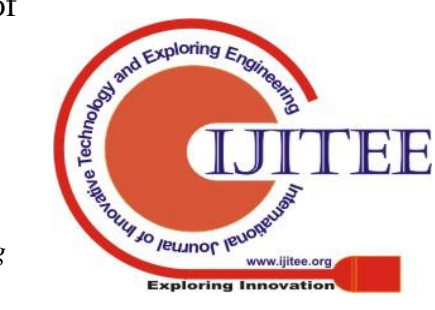


organizations can increase sizable most well liked stance that is knowledgeable to manage well and devour the aptitude to analysis such data blasts over those distinctive firms. At long last, knowledge handling procedures ar used at intervals the malware recognition in mists.

\section{PROPOSED APPROACHES}

We introduce completely different safety efforts which might enhance the safety of distributed computing condition. Since the cloud condition could be a mix of a goodvaries of advancements, we have a tendency to propose completely different arrangements that altogether can influence nature to secure. The planned arrangements support the use of various advances/apparatuses to alleviate the safety issue indicated in past areas. Security proposals unit composed such they're doing not diminish the strength and scaling of cloud frameworks.

The difficulties of security in distributed computing things are sorted into organize level, shopper validation level, data level, and nonspecific issues. System level: The difficulties which may be classified to a lower place a system level hurt organize conventions and system security, as taken hubs, disseminated data, lay to rest hub correspondence. Validation level: The difficulties which may be organized to a lower place shopper confirmation level manages encryption/unscrambling procedures, verification techniques, as Associate in Nursing example, group action rights for hubs, validation of utilizations and hubs, and work. info level :The difficulties which may be sorted to a lower place data level manages data trustworthiness and accessibility like data assurance and circulated data. Bland sorts:

The difficulties which may be classified to a lower place general level region unit antediluvian security apparatuses, and utilization of varied advances.

\section{RESULT AND DISCUSSION}

Truly, there are heaps of huge information security issues and concerns. What's more, truly, they can be very essential. In any case, it doesn't imply that you ought to quickly revile huge information as an idea and never run into it again. No. The thing you ought to do is cautiously structure your huge information appropriation plan making sure to put security to the spot it merits - first. This might be a dubious activity, however you can generally depend on proficient huge information counseling to make the arrangement you need.

Until further notice, information provenance is a wide enormous information concern. From security point of view, it is vital in light of the fact that:

1. Unapproved changes in metadata can lead you to inappropriate informational indexes, which will make it hard to discover required data.

2. Untraceable information sources can be a colossal hindrance to finding the underlying foundations of security ruptures and phony information age cases.

\section{CONCLUSION}

Cloud surroundings are wide utilized in business connected investigation viewpoints; thus security is an essential feature for associations running on these cloud conditions. Abuse anticipated, cloud things are secured for leading edge business operations.

\section{REFERENCES}

1. Kumaravel A., Meetei O.N.,An application of non-uniform cellular automata for efficient cryptography,2013 IEEE Conference on Information and Communication Technologies, ICT 2013,V-,I-,PP-1200-1205,Y-2013

2. Kumarave A., Rangarajan K.,Routing alogrithm over semi-regular tessellations,2013 IEEE Conference on Information and Communication Technologies, ICT 2013,V-,I-,PP-1180-1184,Y-2013

3. Dutta P., Kumaravel A.,A novel approach to trust based identification of leaders in social networks,Indian Journal of Science and Technology,V-9,I-10,PP--,Y-2016

4. Kumaravel A., Dutta P.,Application of Pca for context selection for collaborative filtering,Middle - East Journal of Scientific Research,V-20,I-1,PP-88-93,Y-2014

5. Kumaravel A., Rangarajan K.,Constructing an automaton for exploring dynamic labyrinths,2012 International Conference on Radar, Communication and Computing, ICRCC 2012,V-,I-,PP-161-165,Y-2012

6. Kumaravel A.,Comparison of two multi-classification approaches for detecting network attacks, World Applied Sciences Journal,V-27,I-11,PP-1461-1465,Y-2013

7. Tariq J., Kumaravel A.,Construction of cellular automata over hexagonal and triangular tessellations for path planning of multi-robots,2016 IEEE International Conference on Computational Intelligence and Computing Research, ICCIC 2016,V-,I-,PP--,Y-2017

8. Sudha M., Kumaravel A.,Analysis and measurement of wave guides using poisson method,Indonesian Journal of Electrical Engineering and Computer Science,V-8,I-2,PP-546-548,Y-2017

9. Ayyappan G., Nalini C., Kumaravel A.,Various approaches of knowledge transfer in academic social network,International Journal of Engineering and Technology,V-,I-,PP-2791-2794,Y-2017

10. Kaliyamurthie, K.P., Sivaraman, K., Ramesh, S. Imposing patient data privacy in wireless medical sensor networks through homomorphic cryptosystems 2016, Journal of Chemical and Pharmaceutical Sciences .

11. Kaliyamurthie, K.P., Balasubramanian, P.C.An approach to multi secure to historical malformed documents using integer ripple transfiguration 2016 Journal of Chemical and Pharmaceutical Sciences 9

12. A.Sangeetha,C.Nalini,"Semantic Ranking based on keywords extractions in the web", International Journal of Engineering \& Technology, 7 (2.6) (2018) 290-292

13. S.V.GayathiriDevi,C.Nalini,N.Kumar,"An efficient software verification using multi-layered software verification tool "International Journal of Engineering \& Technology, 7(2.21)2018 454-457

14. C.Nalini,ShwtambariKharabe,"A Comparative Study On Different Techniques Used For Finger - Vein Authentication", International Journal Of Pure And Applied Mathematics, Volume 116 No. 82017 , 327-333, Issn: 1314-3395

15. M.S. Vivekanandan and Dr. C. Rajabhushanam, "Enabling Privacy Protection and Content Assurance in Geo-Social Networks", International Journal of Innovative Research in Management, Engineering and Technology, Vol 3, Issue 4, pp. 49-55, April 2018.

16. Dr. C. Rajabhushanam, V. Karthik, and G. Vivek, "Elasticity in Cloud Computing", International Journal of Innovative Research in Management, Engineering and Technology, Vol 3, Issue 4, pp. 104-111, April 2018 
17. K. Rangaswamy and Dr. C. Rajabhushanamc, "CCN-Based Congestion Control Mechanism In Dynamic Networks", International Journal of Innovative Research in Management, Engineering and Technology, Vol 3, Issue 4, pp. 117-119, April 2018.

18. Kavitha, R., Nedunchelian, R., "Domain-specific Search engine optimization using healthcare ontology and a neural network backpropagation approach", 2017, Research Journal of Biotechnology, Special Issue 2:157-166

19. Kavitha, G., Kavitha, R., "An analysis to improve throughput of high-power hubs in mobile ad hoc network" , 2016, Journal of Chemical and Pharmaceutical Sciences, Vol-9, Issue-2: 361-363

20. Kavitha, G., Kavitha, R., "Dipping interference to supplement throughput in MANET" , 2016, Journal of Chemical and Pharmaceutical Sciences, Vol-9, Issue-2: 357-360

21. Michael, G., Chandrasekar, A.,'Leader election based malicious detection and response system in MANET using mechanism design approach", Journal of Chemical and Pharmaceutical Sciences(JCPS) Volume 9 Issue 2, April - June 2016

22. Michael, G., Chandrasekar, A.,"Modeling of detection of camouflaging worm using epidemic dynamic model and power spectral density", Journal of Chemical and Pharmaceutical Sciences(JCPS) Volume 9 Issue 2, April - June 2016.

23. Pothumani, S., Sriram, M., Sridhar, J., Arul Selvan, G., Secure mobile agents communication on intranet,Journal of Chemical and Pharmaceutical Sciences, volume 9, Issue 3, Pg No S32-S35, 2016

24. Pothumani, S., Sriram, M., Sridhar, Various schemes for database encryption-a survey, Journal of Chemical and Pharmaceutical Sciences, volume 9, Issue 3, Pg NoS103-S106, 2016

25. Pothumani, S., Sriram, M., Sridhar, A novel economic framework for cloud and grid computing, Journal of Chemical and Pharmaceutical Sciences, volume 9, Issue 3, Pg No S29-S31, 2016

26. Priya, N., Sridhar, J., Sriram, M. "Ecommerce Transaction Security Challenges and Prevention Methods- New Approach” 2016 ,Journal of Chemical and Pharmaceutical Sciences, JCPS Volume 9 Issue 3.page no:S66-S68 .

27. Priya, N.,Sridhar,J.,Sriram, M."Vehicular cloud computing security issues and solutions" Journal of Chemical and Pharmaceutical Sciences(JCPS) Volume 9 Issue 2, April - June 2016

28. Priya, N., Sridhar, J., Sriram, M. "Mobile large data storage security in cloud computing environment-a new approach" JCPS Volume 9 Issue 2. April - June 2016

29. Anuradha.C, Khanna.V, "Improving network performance and security in WSN using decentralized hypothesis testing "Journal of Chemical and Pharmaceutical Sciences(JCPS) Volume 9 Issue 2, April - June 2016

\section{AUTHORS PROFILE}

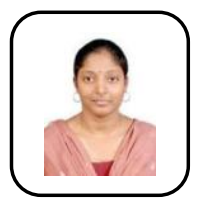

N.Sivaranjani Assistant Professor, Department of Computer science and Engineering, Bharath Institute of Higher Education and Research, Chennai, India

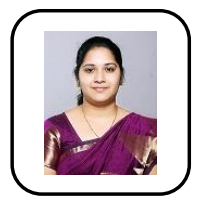

Amudha S Assistant Professor, Department of Computer science and Engineering, Bharath Institute of Higher Education and Research, Chennai, India

Mary Linda I Assistant Professor, Department of Computer science and Engineering, Bharath Institute of Higher Education and Research, Chennai, India 